\title{
Modeling the crucial roles of carbon dioxide in global warming
}

\author{
A. B. M. Shamim. UI Hasan, M. Z. Rahman \\ Department of Applied Mathematics, University of Rajshahi, Rajshahi-6205, Bangladesh \\ Email address: \\ mshamim.appm.ru@gmail.com(A. B. M. Shamim. U1 Hasan), mzillurr@yahoo.com(M. Z. Rahman)
}

\section{To cite this article:}

A. B. M. Shamim. U1 Hasan, M. Z. Rahman. Modeling the Crucial Roles of Carbon Dioxide in Global Warming. American Journal of Environmental Protection. Vol. 2, No. 2, 2013, pp. 72-78. doi: 10.11648/j.ajep.20130202.17

\begin{abstract}
The correspondence between atmospheric carbon dioxide ( $\left.\mathrm{CO}_{2}\right)$ concentrations and globally averaged surface temperatures in the recent past suggest that this coupling may be of great antiquity. Excess greenhouse gases in the atmosphere are a measureable and significant contributor to global warming, and their concentrations have steadily increased over the past century. $\mathrm{CO}_{2}$ is the most important greenhouse gas in terms of climate change, has been measured directly since 1958. In this paper we develop the mathematical model of heat transfer in the atmosphere by $\mathrm{CO}_{2}$, HumanInduced $\mathrm{CO}_{2}$ emission changing the Earth's climate. Additionally, we discussed in this paper are sources, sinks of $\mathrm{CO}_{2}$ and the amounts of naturally produced $\mathrm{CO}_{2}$ and changes in the Earth's climate, which are necessary for understanding the causes of current temperature and $\mathrm{CO}_{2}$ emission trend.
\end{abstract}

Keywords: Global Warming, Climate Change, $\mathrm{CO}_{2}$, Atmosphere, Emission

\section{Introduction}

Carbon dioxide $\left(\mathrm{CO}_{2}\right)$ is an important greenhouse gas, and its role in regulating global surface temperatures has been recognized for over a century [2], [5]. It is now generally accepted that the $36 \%$ rise in atmospheric $\mathrm{CO}_{2}$ since $1860(280-380 \mathrm{ppm})$ is partly responsible for the concomitant rise in global surface temperatures [9], [10], [16]. Moreover, ice core records indicate a strong coupling between $\mathrm{CO}_{2}$ and temperature for at least the last 650,000 years [20]. Given this observed, positive relationship between $\mathrm{CO}_{2}$ and temperature and the physical laws that govern it, and a priori expectation is that the $\mathrm{CO}_{2}$ temperature link is of great antiquity.

The hypothesis that increased greenhouse gas (such as $\mathrm{CO}_{2}$ ) concentrations may lead to a rise in global temperatures first emerged in the 1960s [17]. The overwhelming majority of climate scientists now agree that the evidence for anthropogenic global warming is strong [18]. Climate change may be one of the most disruptive phenomena of the twenty-first century. Predictions of average temperature changes and the economic costs of climate change are uncertain, but generally bleak: for increases of $5-6{ }^{\circ} \mathrm{C}$, which is a "Business as Usual" scenario, the predicted economic loss is $5-10 \%$ of global [23].

The temperature of Earth's atmosphere is increasing. During the 20th century, the mean global land-ocean temperature has increased by approximately $.6{ }^{0} \mathrm{C}$ (Fig. 1). According to the proponents of conventional global warming theory, over the same period of time, the concentrations of water vapor, $\mathrm{CO}_{2}$, methane and other greenhouse gases (nitrous oxide, troposphere ozone) in the atmosphere increased as a result of the human utilization of oil, gas, and coal. $\mathrm{CO}_{2}$ is the primary greenhouse gas emitted through human activities. In 2011, $\mathrm{CO}_{2}$ accounted for about $84 \%$ of all greenhouse gas emissions from human activities. The increasing concentration of $\mathrm{CO}_{2}$ from 2004 to 2009 , for example, is illustrated in Fig. 2.

Increasing concentrations of greenhouse gases may also accelerate climate changes. Environmentalists predict that the global surface temperature could rise $1-4.5^{\circ} \mathrm{F}$ in the next 50 years, and $2.2-10^{\circ} \mathrm{F}$ in the next century [8]. Because of the rising temperature, evaporation will increase, which, in turn, will increase global precipitation. The intense rainstorms around the world will become more 
frequent. Ice melting will increase the global sea level, which will be likely to rise $0.6 \mathrm{~m}$ in the next 50 years around the world. These disastrous climatic changes are usually attributed to the greenhouse effect. The latter is commonly blamed on the increase in man induced $\mathrm{CO}_{2}$ emission.

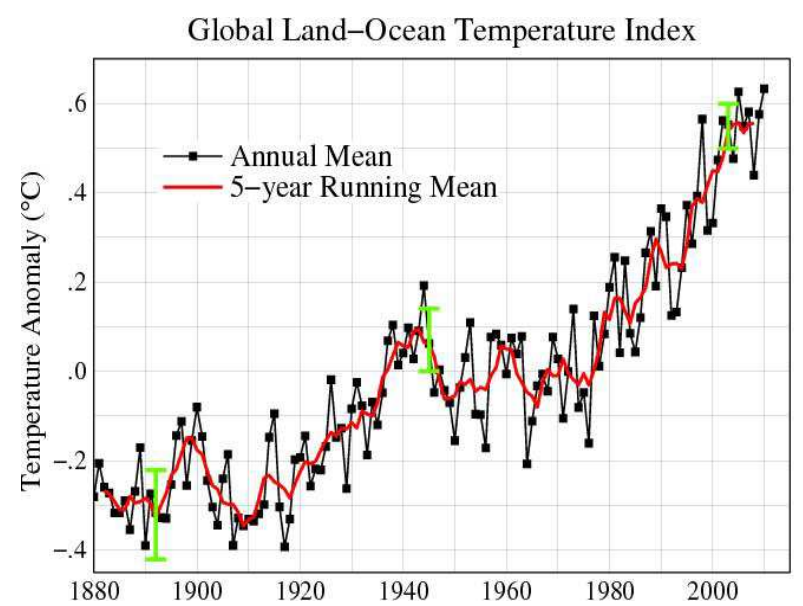

Figure 1. Global mean land-ocean temperatures change from 1880-2010, relative to the 1951-1980 mean. The black line is the annual mean and the red line is the 5-year running mean. The green bars show uncertainty estimates. Source: Data from NASA GISS

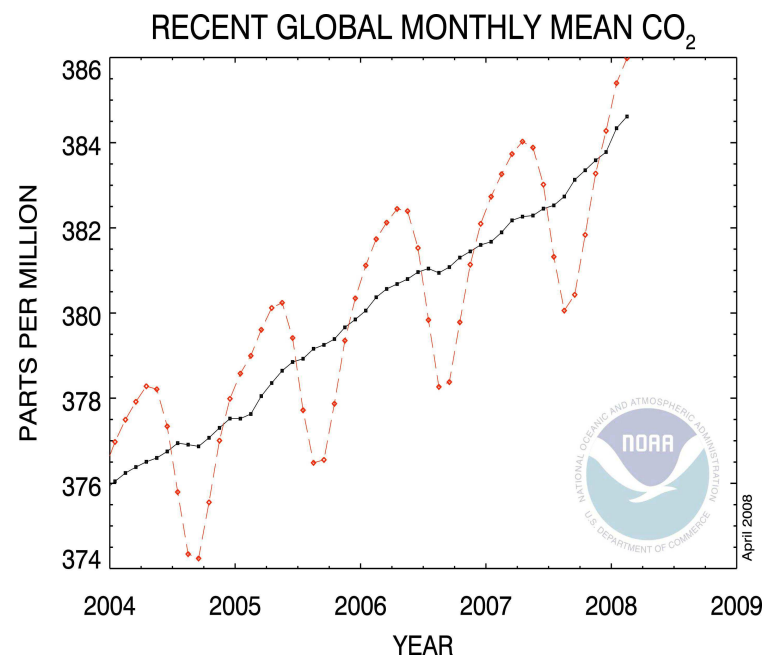

Figure 2. $\mathrm{CO}_{2}$ emission from 2004-2009, By Source: Data from NRC (2010) U.S

\section{Sources and Sinks of $\mathrm{CO}_{2}$}

First doubt on the leading role of the human-induced $\mathrm{CO}_{2}$ emission into the atmosphere is cast if one superposes the graphs of $\mathrm{CO}_{2}$ concentration in the atmosphere and $\mathrm{CO}_{2}$ emission to the atmosphere due to burning fossil fuel (Fig.3)

If the burning of fossil fuels were the main cause (or one of the main causes) of the steadily increasing $\mathrm{CO}_{2}$ content in the atmosphere, then the atmospheric concentration should also stop rising or at least its rate of rise should be reduced. This did not occur. The burning fossil fuels are not the major source of $\mathrm{CO}_{2}$ in the atmosphere and, therefore, is not the main cause of the greenhouse effect. The second natural step is identifying and evaluating the volumes of $\mathrm{CO}_{2}$ inflow from the major natural sources into the atmosphere ocean system of the Earth. The rate of total human-induced $\mathrm{CO}_{2}$ emission to the Earth's atmosphere is currently about 5-7 billion tons/ year [19]. Yet, estimates by [24] show that the $\mathrm{CO}_{2}$ emission only from the volcanic activity at the mid ocean ridges accounts for about 20-30 billion tons/per year. The oceanic water contains 50-60 times more $\mathrm{CO}_{2}$ than the atmosphere and is a major supplier of $\mathrm{CO}_{2}$ to the atmosphere. As was recently shown [21], [11], [12], a rising temperature drives huge volumes of $\mathrm{CO}_{2}$ from the ocean water to the atmosphere. In a recent publication [4], researchers at the Lawrence Livermore National Laboratory have stated that "continued release of $\mathrm{CO}_{2}$ during the next several centuries would increase ocean acidity more rapidly than during the past 300 million years". This conclusion was made based on computer models. Once again, the burning of fossil fuels was named as a dominating source of increase in the $\mathrm{CO}_{2}$ concentration (and carbonic acid) in the ocean water "because eventually the ocean absorbs most of this $\mathrm{CO}_{2}$.

At this point, it should be noted that the world ocean plays a dual role in the carbon cycle (putting aside living matter involved in the carbon transformation). Depending on the changing climatic conditions, oceans can be either a " sink for" or "source of" the atmospheric $\mathrm{CO}_{2}$. If, for example, the global temperature rises, then solubility of the $\mathrm{CO}_{2}$ in the oceanic water decreases, and part of the oceanic $\mathrm{CO}_{2}$ will be transferred to the atmosphere to maintain continuous dynamic equilibrium.

Global Carbon Dioxide Emissions from Fossil Fuel Burning, 1751-2009

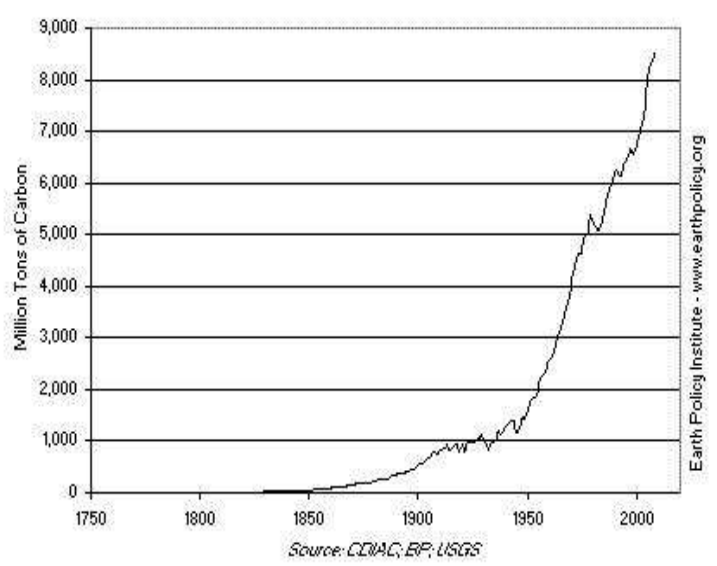

Figure 3. Global $\mathrm{CO}_{2}$ emission from fossil fuel burning, 1751-2009. Source: Data from CDIAC, BP, USGS 


\section{Mathematical Model of Heat Transfer in the Atmosphere by Roles of $\mathrm{CO}_{2}$}

Huge potential damage to the world economy led to the revision and subsequent serious critique of the basic assumptions made in the studies on global warming [21], [3]. Thorough examination of the alarming predictions showed that until recently the theory of greenhouse effect did not exist, and all the numerical calculations and predictions were based on simplified mathematical models with rough estimates of the important parameters. One of the simplified one-layer models was presented by [12].

In this model one-layer atmosphere was assumed to be confined by two imaginary surfaces: bottom (representing the Earth's surface absorbing and reradiating back to space the solar radiation) and top (representing reflecting properties of the Earth-atmosphere system, or Earth's albedo - fraction of the solar radiation that is reflected back into space). The Stefan-Boltzmann Law [14] was applied for calculation of the surface temperature of the planet for several global warming scenarios with various parameters of the Earth's albedo, atmospheric attenuation of the solar radiation, and the greenhouse effect. Mester's model showed that the greenhouse effect did contribute to the global warming. The above discussed model counts on the heat transfer in the atmosphere by radiation only. It is worth noting that the heat transfer by radiation dominates in the upper diffuse layers of the stratosphere, mesosphere and thermosphere only. Meantime, Earth has a relatively dense atmosphere [15] and the heat transfer in its lower, denser, layer (troposphere) mostly occurs by convection [21].

Indeed, in the troposphere, with the air pressure exceeding $0.2 \mathrm{~atm}$, heat transfer by convection is dominating. When the temperature of a given mass of air increases, its volume also increases. As the hot air expands, it becomes less dense, and rises. In turn, the denser cooler air drops and replaces the warmer air [12]. This system works in the Earth-atmosphere system as a continuous surface cooler. The cooling effect of the air convection in the troposphere can considerably surpass the warming greenhouse effect. The most important conclusion from this observation is that the temperature distribution in the troposphere has to be close to adiabatic taking into consideration the fact that the air mass expands and cools while rising, and compresses and heats while dropping [21]. This hypothesis was indirectly verified by comparison of theoretical and experimental distributions of the temperature in the troposphere of the Earth (and Venus) that was done by [22]. For adiabatic transformation, the temperature dependence on gas pressure can be presented in the following form [14].

$$
T=C_{\alpha} P_{\alpha}
$$

Where $\mathrm{C}$ a is a constant defined separately. The exponent $\alpha$ in equation (1) is defined by

$$
\alpha=\left(C_{P}-C_{V}\right) / C_{P}
$$

Where $C_{P}$ and $C_{V}$ are the thermal capacities of the gas at a constant pressure and for a constant volume, respectively.

For $\mathrm{CO}_{2}$ and $\mathrm{H}_{2} \mathrm{O}, \alpha=0.2308$; whereas for $\mathrm{O}_{2}$ and $\mathrm{H}_{2}$, $\alpha=0.2857$. Water vapor condensing in the troposphere emits the heat that increases the air temperature. Because of that, the adiabatic exponent $\alpha$ decreases. For example, for the humid Earth's troposphere $\alpha=0.1905$ [22]. Water vapor condensing in the troposphere produces cloudiness, which is a leading factor that determines the Earth's albedo. This forms a strong negative feedback between the solar radiation and the Earth's surface heating, which stabilizes the troposphere temperature. Under these circumstances, one can assume that the troposphere temperature is a linear function of the effective radiation temperature (temperature of absolutely black body at a distance from Sun to Earth). Combining this condition with equation (1), one can write a formula that determines the "average Earth's surface temperature", at any altitude of the troposphere as an exponential function of the pressure at the same altitude:

$$
T(h)=b T_{e} P^{\alpha}(h)
$$

Where $p(h)$ is the pressure of the atmosphere at the altitude $h, T(h)$ is the "average surface temperature" at the altitude $\mathrm{h}, T_{e}$ is the effective radiation temperature, and $\mathrm{b}$ is a scaling coefficient.

For Earth, $T_{e}=278.8 \mathrm{~K}$; contemporary temperature at the sea level is equal to $288 \mathrm{~K} ; \mathrm{T}(0)=288 \mathrm{~K}$; and the atmospheric pressure $\mathrm{p}(0)=1 \mathrm{~atm}$. Substituting these data into equation (3), we get $(288=\mathrm{b} \times 278.8 \times 1)$, one can determine the scaling coefficient $b \quad(b=1.033)$. Thus, rewriting equation (3) in a more convenient form, one obtains:

$$
T(h)=1.033 T_{e} P^{\alpha}(h)
$$

Or

$$
T(h)=288 P^{\alpha}(h)
$$

This allows the construction of the temperature distribution for the troposphere (if the exponent $\alpha$ is known). Under such approach, the focus of modeling is shifted to the definition of parameter a, which determines the adiabatic heat transfer in the troposphere. [22] Associates computed the values of $\alpha$ for typical conditions of the troposphere: for the absolutely dry and transparent troposphere $\alpha=0.286$; and for the humid, heat absorbing troposphere $\alpha=0.1905$ [22]. The temperature distributions in the troposphere for these two conditions are shown in Figure. 4

In this figure, one can see that for the same atmospheric pressure the near surface temperature of the dry and transparent troposphere is always greater than the near 
surface temperature for the humid, heat-absorbing troposphere. The heat absorption by the greenhouse gases $\left(\mathrm{CO}_{2}\right)$ causes further increase in this difference. This leads to paradoxical (at first sight) conclusion that absorption of the infrared radiation by the Earth's atmosphere does not increase, but, on the contrary, decreases the near-surface temperature of the atmosphere. Using the adiabatic model, the explanation becomes simple: with increasing effective thermal capacity of the air (that occurs if the emission of the greenhouse gases $\left(\mathrm{CO}_{2}\right)$ to the atmosphere increases), the adiabatic exponent a decreases, and the atmospheric temperature decreases (in accordance with Eq. 4). Physical explanation of the latter lies in the high efficiency of heat transfer by convection from the planet surface to the lower layers of the stratosphere from which the heat is rapidly emitted to space by radiation. The major flaw of the radiation theory of global warming is that it ignores completely the heat transfer in atmosphere by convection. Of the total heat transfer from the Earth's surface to the troposphere, convection $\left(\mathrm{CO}_{2}\right)$ accounts for $67 \%$, radiation $\left(\mathrm{CO}_{2}\right)$ accounts for $11 \%$, and the condensation of water vapor in troposphere accounts for $22 \%$ [21].

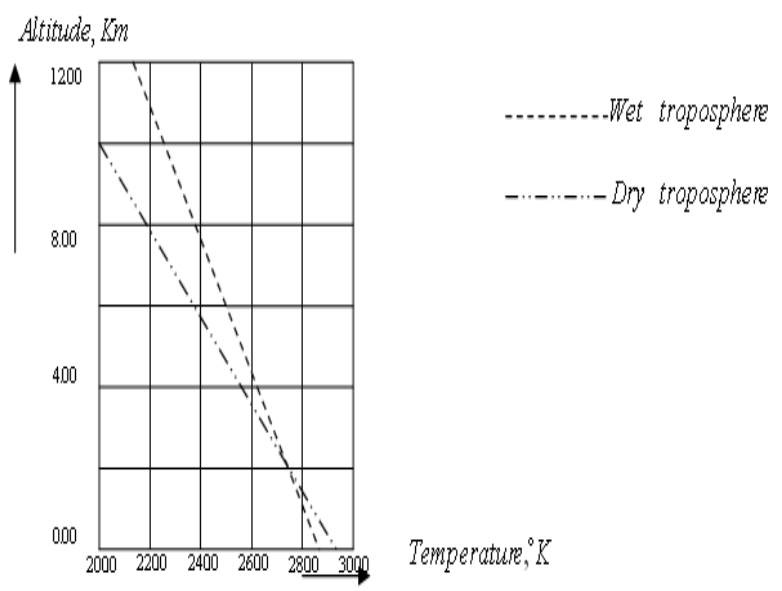

Figure 4. Adiabatic temperature distribution in troposphere for dry troposphere ( $\alpha=0.286$ ) and wet troposphere ( $\alpha=0.1905)$ (modified after 2001 [21])

\section{Human-Induced $\mathrm{CO}_{2}$ Emission Changing the Earth's Climate}

The concentration of $\mathrm{CO}_{2}$ in the Earth's atmosphere has been increasing in the last century. The carbon content in the atmosphere was increasing by approximately 3 billion tons/year at the end of the century. The rate of the total human-induced $\mathrm{CO}_{2}$ emission to the Earth's atmosphere is currently about 5-7 billion tons/ year [19]. This amount of $\mathrm{CO}_{2}$ not only changes the gas composition of the atmosphere, but also slightly increases the atmospheric pressure. One can use the adiabatic model together with the sensitivity analysis [13], [11], to evaluate the effect of human-induced emission of the $\mathrm{CO}_{2}$ on the global temperature. Taking logarithms of both sides of equation (5) results in:

$$
\ln T=\ln 288+\alpha \ln P
$$

Introducing notation $\mathrm{A}(\alpha, \mathrm{p})$ for the right part of equation (6), one can find the sensitivity functions of $\ln T$ as partial derivatives of $\mathrm{A}(\alpha, \mathrm{p})$ with respect to parameters $\alpha$ and $\mathrm{p}$.

Differentiating equation (6), one obtains:

$$
\frac{1}{T} d t=\frac{\partial A(\alpha, p)}{\partial \alpha} d \alpha+\frac{\partial A(\alpha, p)}{\partial p} d p
$$

Substituting partial derivatives of $\mathrm{A}(\alpha, \mathrm{p})$ and multiplying both sides of equation (7) by $\mathrm{T}$, the following equation is obtained:

$$
d T=T\left(\ln p d \alpha+\frac{\alpha}{p} d \alpha\right)
$$

Transition to finite differences in differential equation (8) yields:

$$
\Delta T \approx T \ln p \Delta \alpha+T \frac{\alpha}{p} \Delta p
$$

Equation (9) is convenient for the analysis of the effect of human-induced emission of greenhouse gases on the global temperature. If, for example, the concentration of $\mathrm{CO}_{2}$ in the atmosphere increases two times (from 0.035 to $0.07 \%$ ), which is expected by the year 2100 , then the pressure will increase by $\Delta p=1.48 \times 10^{-4}$ atm, and $\Delta \alpha=-4 \times 10^{-6}[21]$. At the sea level, if the pressure is measured in atmospheres, then $\mathrm{p}=1$, and $\ln p=0$. Thus,

$$
\Delta T \approx T \alpha \Delta \alpha
$$

After substitution of $\mathrm{T}=288 \mathrm{~K}, \quad \alpha=0.1905$, and $\Delta p=1.48 \times 10^{-4}$ atm into equation (10), one finds $\Delta T \approx 8.12 \times 10^{-3}$. Thus, the increase in the surface temperature at the sea level caused by the human-induced $\mathrm{CO}_{2}$ emission will be less than $0.01 \mathrm{~K}$, which is negligible, compared to the natural temporal fluctuations of the global temperature. This increase will be slightly higher at the higher altitudes, where the pressure is less than one atmosphere, and its logarithm is negative. Multiplication of $\ln p$ by the negative value of $\Delta \alpha$ will increase $\Delta T$ (the global temperature change) (Equation-9). If, for example, $\mathrm{h}=10 \mathrm{~km}$, then the barometric pressure $p \approx 0.24 \mathrm{~atm}$ and the temperature is about $200-220 \mathrm{~K}$ [6]. Substituting all necessary data $(\mathrm{T}=220 \mathrm{~K}, p \approx 0.24$ atm, $\ln p \approx-1.4286$, $\Delta p=1.48 \times 10^{-4}$ atm, $\alpha=0.1905, \Delta \alpha=-4 \times 10^{-6}$ ) into equation (9), one obtains $\Delta T \approx 2.710 \times 10^{-2} \mathrm{~K}$, which is less than $0.03 \mathrm{~K}$. From these estimates, one can deduce a very 
important practical conclusion that even considerable increase in the human-induced emission of $\mathrm{CO}_{2}$ and other greenhouse gases practically does not change the global atmospheric temperature. Thus, the hypothesis of current global warming resulting from the increased emission of greenhouse gases into the atmosphere is a myth. Humans are not responsible for the increase in the global surface temperature of $1^{\circ} \mathrm{F} \approx 0.56 \mathrm{~K}$ during the last century, and one should look for natural sources for heating of the atmosphere.

\section{Emissions and Trends of $\mathrm{CO}_{2}$}

Proponents of the greenhouse global warming theory usually point out that the increased emission of greenhouse gases $\left(\mathrm{CO}_{2}\right)$ is accompanied by the increase in global temperature, and, consequently, the increased emission causes the global warming.

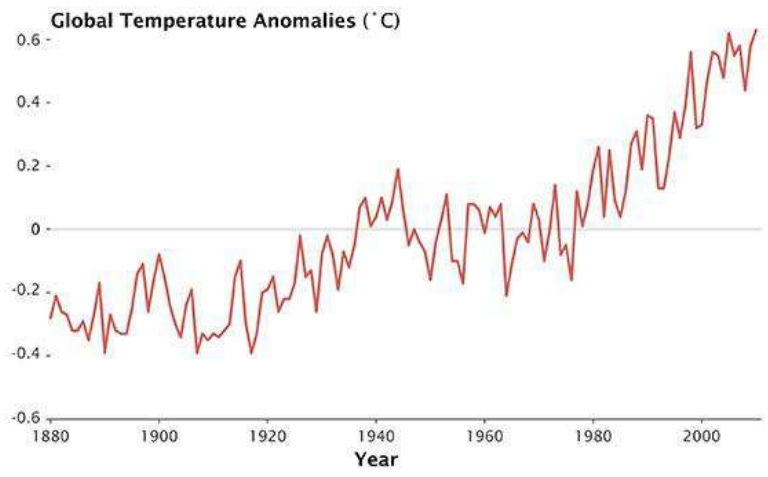

Figure 5. Global temperature trend from 1880 to present compared to a base period of 1951-1980. Global temperatures continue to rise, with the decade from 2000 to 2009 as the warmest on record Source: NASA/Earth Observatory/Robert Simmon
Global average surface temperatures have increased markedly over the last century (Figure 5). Humans have been measuring temperature directly since the mid-1800's; these measurements show that temperature increased by $1.33^{\circ} \mathrm{F}\left(0.74^{\circ} \mathrm{C}\right)$ between 1906 and 2005 , and that the rate of warming is increasing [7]. The decade from January 2000 to December 2009 was the warmest decade during this time period [16]. Although $1.33^{\circ} \mathrm{F}$ may not seem like a large temperature change, on a global scale this has huge implications for many of the earth's processes that affect ecosystems and humans. To put the number in perspective, many scientists think that temperature increases in excess of $3.6^{\circ} \mathrm{F}\left(2.0^{\circ} \mathrm{C}\right)$ relative to $1980-1999$ will result in 'dangerous' climate change; others say that even lesser increases would be enough to create outcomes dangerous to human civilization [1].

Excess greenhouse gases in the atmosphere are a measureable and significant contributor to global warming, and their concentrations have steadily increased over the past century [8]. $\mathrm{CO}_{2}$ is the most important greenhouse gas in terms of climate change, has been measured directly since 1958. Additionally, atmospheric levels of $\mathrm{CO}_{2}$ can be reconstructed for hundreds of thousands of years into the past using methods such as analyzing air bubbles trapped in ice. $\mathrm{CO}_{2}$ Concentration in late 2011 was at 391 parts per million, a level that is higher than at any point during the past 400,000 years [7]. Growth rates of atmospheric $\mathrm{CO}_{2}$ are still high, with 2010 experiencing one of the largest annual growth rates of the past decade [7] and Comparisons between the global view site data and the interpolation results of near surface $\mathrm{CO}_{2}$ from SCIAMACHY ( satellite observations ) data in Fig. 7

\section{Trends in Atmospheric $\mathrm{CO}_{2} \&$ Global Surface Temperature}

The last 400,000 Years

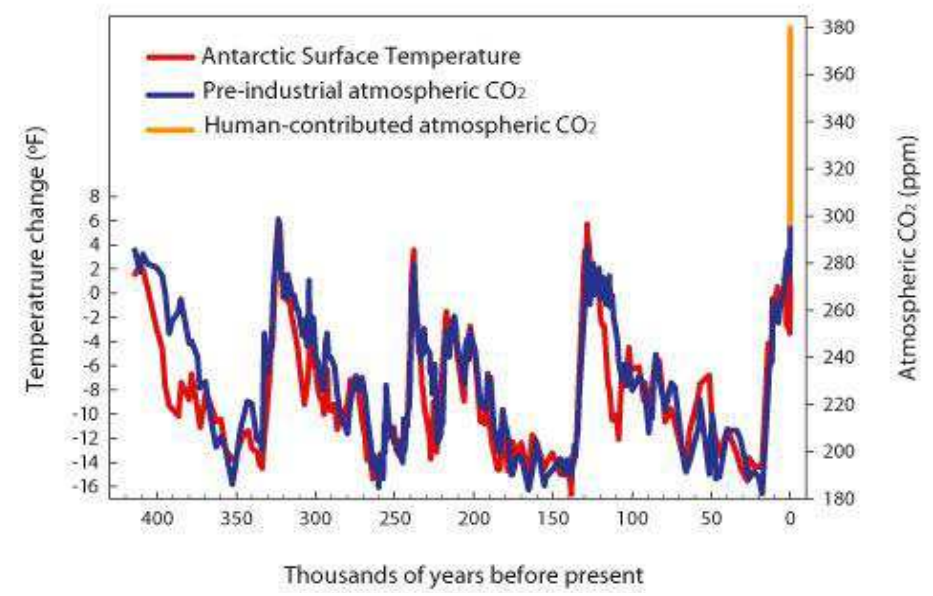

Figure 6. Human society is entering uncharted territory as atmospheric levels of greenhouse gases continue to rise. Today's $\mathrm{CO}_{2}$ levels are substantially higher than anything that has occurred for more than 800,000 years (last 400,000 years pictured here). Source: Center for Climate and Energy 

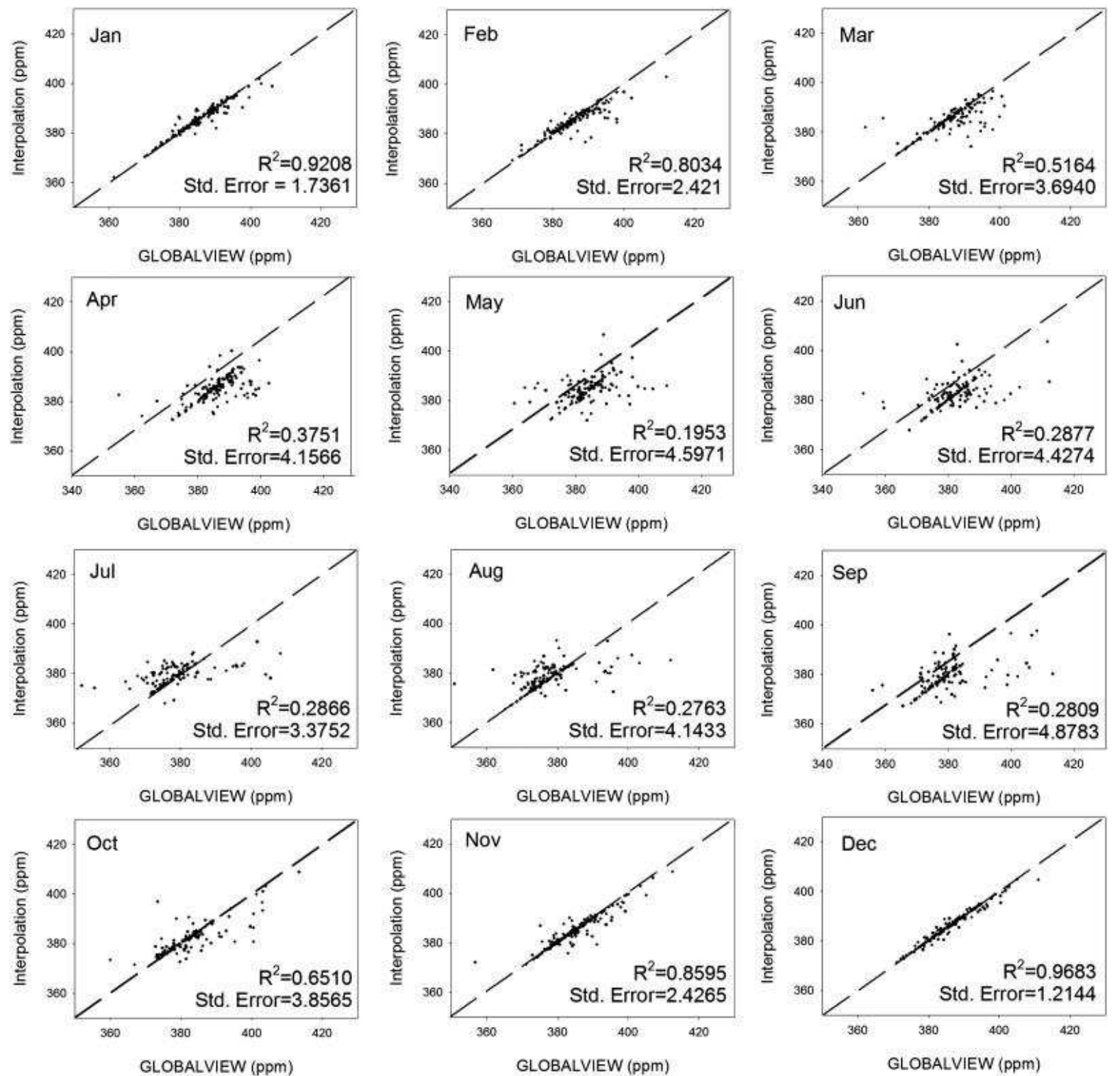

Figure 7. Comparisons between the global view site data and the interpolation results of near surface $\mathrm{CO}_{2}$ from SCIAMACHY data. Source: Data from Science direct

\section{Conclusions}

As a result of increased temperature, $\mathrm{CO}_{2}$ from the ocean water is transferred to the atmosphere. Thus, one can see that "cause" and "effect" are reversed, as presented by proponents of the theory of global warming due to an increase in $\mathrm{CO}_{2}$ emission by humans. The adiabatic model presented here adequately describes the heat transfer in the Earth-atmosphere system and, together with the sensitivity theory, may be used for the quantitative analysis of temperature changes in the atmosphere due to contents of gases $\left(\mathrm{CO}_{2}\right)$ and their concentrations.

Also the role of $\mathrm{CO}_{2}$ on the process of atmospheric heating, finding a political solution to the problem of global warming seems to be very difficult if at all possible. Following the logic of the authors of the Kyoto Protocol, all the countries around the world must dramatically cut, not only the energy production, but also cattle growing, rice production, and production of oil, gas, and coal, because all of these activities produce huge amounts of $\mathrm{CO}_{2}$. Consequently, severe restrictions will be imposed on the rate of the world population growth.

\section{Acknowledgements}

The authors would like to acknowledge Dr. M. Ali Akbar for his comments and encouragement.

\section{References}

[1] Anderson A.; Bows, A. 2011. Beyond 'dangerous' climate change: emission scenarios for a new world. Philosophical 
Transactions of the Royal Society. 369: 20-44.

[2] Arrhenius S (1896) On the influence of carbonic acid in the air upon the temperature of the ground. Phil Mag 41: 237276

[3] Baliunas SL (2002) The Kyoto Protocol and global warming. Imprimis 31(3): 1-7; http://www.hillsdale.edu

[4] Caldeira K, Wickett $\mathrm{M}$ (2003) Anthropogenic $\mathrm{CO}_{2}$ and ocean $\mathrm{pH}$. Nature 425(6956): 365

[5] Chamberlin, T.C., 1899. An attempt to frame a working hypothesis of the cause of glacial periods on an atmospheric basis. J. Geol. 7, 545-584.

[6] FMH-1 (1995) Federal meteorological handbook, no.1: http:// www.nws.noaa.gov/oso/oso1/oso12/fmh1

[7] Global Carbon Project. 2011. Carbon budget and trends 2010. (Accessed 12-8-2011)

[8] IPCC, 2007a: Climate Change 2007: The Physical Science Basis. Contribution of Working Group I to the Fourth Assessment Report of the Intergovernmental Panel on Climate Change [Solomon, S.; Qin, D.; Manning, M.; Chen, Z.; Marquis, M.; Averyt, K.B.; Tignor, M.; Miller, H.L. (eds.)]. Cambridge University Press, Cambridge, United Kingdom and New York, NY, USA.

[9] Karl, T.R., Trenberth, K.E., 2003. Modern global climate change. Science 302, 1719-1723.

[10] Karoly, D.J., Braganza, K., Stott, P.A., Arblaster, J.M., Meehl, G.A., Broccoli, A.J., Dixon, K.W., 2003. Detection of a human influence on North American Climate. Science $302,1200-1203$.

[11] Katz SA, Khilyuk LF, Chilingar GV (1996) Sensitivity analysis and multivariant modeling for formation pressure and temperature fields in inhomogeneous media. J Petrol Sci Eng 16: 95-108

[12] Khilyuk LF, Chilingar GV, Al-Hamdan MR (2003) Global warming and petroleum industry. Abstracts of SPE Conference.

[13] Khilyuk LF, Katz SA, Chilingarian GV, Aminzadeh F (1994)
Numerical criterion and sensitivity analysis for time dependent formation pressure in a sealed layer. J Petrol Sci Eng 12: $137-145$

[14] Landau LD, Lifshits EM (1979) Statistical physics (in Russian). Nauka, Moscow, 484 pp

[15] Marov MYa (1986) Planets of the solar system (in Russian). Nauka, Moscow, 320 pp

[16] Miller, K.G., Sugarman, P.J., Browning, J.V., Kominz, M.A., Olsson, R.K., Feigenson, M.D., NASA - Goddard Institute for Space Studies. 2011. NASA Research Finds 2010 Tied for Warmest Year on Record. Research News

[17] Peterson T, Connolley W, Fleck J (2008) The myth of the 1970s global cooling scientific consensus. Bull Am Meteorol Soc 89: 1325-1337

[18] osenberg S, Vedlitz A, Cowman D, Zahran S (2010) Climate change: a profile of U.S. climate scientists' perspectives. Clim Chang 101(3-4): 663-668

[19] Schimel DS (1995) Global change biology 1: 77-91

[20] Siegenthaler, U., Stocker, T.F., Monnin, E., Lu“ thi, D., Schwander, J., Stauffer, B., Raynaud, D., Schwander, J.,Stauffer, B., Raynaud, D., Barnola, J.-M., Fischer, H., Masson-Delmotte, V., Jouzel, J., 2005. Stable carbon cycleclimate relationship during the late Pleistocene. Science 310 , 1313-1317.

[21] Sorokhtin OG (2001) Greenhouse effect: myth and reality (in Russian). Vestnik of Russian Academy of Natural Sciences 1(1): 8-21

[22] Sorokhtin OG, Ushakov SA (1999) Greenhouse effect and global evolution of the Earth climates (in Russian). Izvestiya of Russian Academy of Natural Sciences 3: 82101

[23] Stern N (2007) The economics of climate change: The Stern review. Cambridge University Press, Cambridge

[24] Yasamanov NA (2003) Modern global warming: causes and ecological consequences (in Russian). Bull Dubna Int University for Nature, Society, and Man 1(8): 12-21. 